2 Hendrickson MR, Kempson RL. Endometrial hyperplasia, metaplasia and carcinoma. In: Fox $\mathrm{H}$, ed. Haines and Taylor obstetrical and Fox H, ed. Haines and Taylor obstetrical and gynecological pathology. Edinb

3 Crocker J, Skilbeck NQ. Nucleolar organiser region-associated proteins in cutaneous melanocytic lesions: a quantitative study. Clin Pathol 1987;40:885-9.

4 Howat AJ, Giri DD, Cotton DWK, Slater DN Nucleolar organiser regions in Spitz nevi and malignant melanomas. Cancer 1989;63:474-8.

5 Ausens EWMA, van der Kamp J-K, Baak JPA Nuclear morphometry in the determination of the prognosis of marked atypical endometrial hyperplasia. Int J Gynecol Pathol $1985 ; 4: 180-5$.

Reproducible test for detecting Helicobacter pylori in frozen samples

Retrospective investigations of Helicobacter pylori in stored samples might help us to understand the aetiological role of Helicobacter pylori in different lesions with which it has been associated.' Helicobacter pylori, however, is a fastidious micro-organism, and it is difficult to store it without pronounced loss of viability. ${ }^{2}$ Some investigators have studied the presence of Helicobacter pylori in stored samples using stained sections, ${ }^{3}$ but no one has evaluated the reproducibility of a method to detect Helicobacter pylori in stored samples.

The aim of this study was to evaluate prospectively the accuracy of a simple and rapid urease test and culture techniques for the detection of Helicobacter pylori in infected frozen gastric biopsy specimens.

A total of 52 antral gastric biopsy specimens were included in the study. The biopsy specimens were ground in $1 \mathrm{ml}$ of $20 \%$ sterile glucose chilled transport medium with the $\mathrm{pH}$ adjusted to $6 \cdot 8$. A fraction of each specimen was processed for culture and rapid urease test assay. The remaining parts of the homogenised specimens were divided into three groups and stored at $-70^{\circ} \mathrm{C}$. The groups were reanalysed at different times (two, four, and six months after endoscopy) by again using the rapid urease test and culture.

The culture was performed on Skirrow's Campylobacter agar (Difco Laboratories, Detroit, Michigan), trypticase soy agar (Difco) supplemented with $7 \%$ horse blood, $1^{\circ}$. IsoVitalex, and with or without antibiotics $(10 \mathrm{mg} / 1$ vancomycin, $5 \mathrm{mg} / 1$ trimethoprim lactate, and $2500 \mathrm{IU} / 1$ polymixin B), chocolate agar, and Thayer-Martin agar (BBL) with $1 \%$ IsoVitalex and $2 \%$ haemoglobin. Plates were incubated at $37^{\circ} \mathrm{C}$ for up to seven days in a Campy Pak (BBL) generating microaerophilic or a Campylobacter gas generating Kit (Oxoid Ltd, London, England).

The rapid urease test used in a modification of that used by Arvind et $a l^{4}{ }^{4}$ and recently validated in our laboratory, ${ }^{5}$ can be performed with a very small amount of homogenised tissue incubated at $55^{\circ} \mathrm{C}$.

Culture of the fresh homogenised specimens identified Helicobacter pylori in 42 of the 52 biopsy specimens tested, a positive rapid urease test being observed in all 42 that were positive by culture. The rapid urease test performed after two, four, and six months of freezing was also positive in all the samples that were positive before storage. Although the rapid urease test was $100 \%$ reproducible at any time, a decrease in the activity of the enzyme was observed.

The culture of the stored specimens that were Helicobacter pylori positive in the fresh analysis identified the micro-organism in 14 of $16(87 \%)$ specimens after two months, 14 of $15(93 \%)$ after four months, and 10 of 11 $(91 \%)$ after six months. The viability determined by the number of colony forming units was reduced from $20 \%$ to $80 \%$ after freezing. This loss, however, was related to the initial number of colonies rather than the time of freezing.

None of the 10 Helicobacter pylori negative samples in the fresh examination gave a positive culture or rapid urease test when analysed at two, four, or six months.

These results indicate that despite freezing and greatly reducing the viability of the micro-organism, the urease enzyme remains sufficiently active after six months of freezing to give positive results at $55^{\circ} \mathrm{C}$. We conclude that the modified rapid urease test is more accurate than culture in identifying Helicobacter pylori in frozen gastric mucosal specimens and, therefore, it is the most convenient method for retrospective studies.

$S$ ABDALLA, F MARCO, RM PEREZ

Departments of Gastroenterology and Microbiology, Hospital Clinic, Villarroel 170, Spain

1 Warren JR, Marshall BJ. Unidentified curved bacilli on gastric epithelium in active chronic bacilli on gastric epithelium in

2 Westblom TU, Barthel JS, Havey AD Gonzalez FJ, Tarka EF, Everett Ed. J Clin Gonzalez FJ, Tarka E.

3 Walters LL, Budin RE, Paull G. Acridine orange to identify Campylobacter pylori in formalin fixed paraffin-embedded gastric biopsies. Lancet 1986;i:42.

4 Arvind AS, Cook RS, Tabaqchali S, Farthing MJG. One-minute endoscopy room test for Campylobacter pylori. Lancet 1988;i:704

5 Abdalla S, Marco F, Pérez RM, et al. Rapid detection of gastric Campylobacter pylori detection of gastric Campylobacter pylori Clin Microbiol 1989;27:2604-5.

\section{Acute phase response and deep lower limb venous thrombosis}

The acute phase response with fever, a neutrophil leucocytosis, and increased concentrations of plasma proteins may be induced by different infectious, ischaemic, immunological, malignant, or traumatic stimuli. One of the most practical methods for monitoring it is to quantify the serum Creactive protein (CRP) concentration. ${ }^{1}$ The purpose of the present work was to compare the acute phase response in different types of deep lower limb thrombosis.

Forty five patients with deep lower limb thrombosis verified by ascending phlebography were studied. These patients did not have

Characteristics of 45 patients with deep lower limb venous thrombosis

\begin{tabular}{|c|c|c|c|c|c|c|c|c|}
\hline & \multicolumn{2}{|c|}{$\begin{array}{l}\text { Tibial/popliteal } \\
(n=26)\end{array}$} & \multicolumn{2}{|c|}{$\begin{array}{l}\text { Iliofemoral } \\
(n=19)\end{array}$} & \multirow{2}{*}{$\begin{array}{l}\text { Mean } \\
\text { difference }\end{array}$} & \multirow{2}{*}{$\begin{array}{l}95 \% \text { confidence } \\
\text { interval }\end{array}$} & \multirow[b]{2}{*}{$t$ test } & \multirow[b]{2}{*}{$p$ valu } \\
\hline & Mean & $(S D)$ & Mean & $(S D)$ & & & & \\
\hline $\begin{array}{l}\text { Age (years) } \\
\text { Leucocytosis } \\
\text { Taxt }\end{array}$ & $\begin{array}{r}52.6 \\
8.7 \\
37.0\end{array}$ & $\begin{array}{r}14 \cdot 7 \\
1.9 \\
0 \cdot 4\end{array}$ & $\begin{array}{r}66 \cdot 5 \\
8 \cdot 6 \\
36 \cdot 9\end{array}$ & $\begin{array}{r}15.6 \\
1.6 \\
0.3\end{array}$ & $\begin{array}{r}13.9 \\
-\quad 0.1 \\
-0.1\end{array}$ & $\begin{array}{r}4.8 \text { to } 23.1 \\
-1.2 \text { to } 1.0 \\
-0.4 \text { to } 0.1\end{array}$ & $\begin{array}{r}3.1 \\
-0.2 \\
-1.0\end{array}$ & $\begin{array}{l}0.004 \\
0 \cdot 86 \\
0.34\end{array}$ \\
\hline
\end{tabular}

*-maximum of peripheral blood leucocyte counts, $\times 10^{9} / 1$

$\mp-$ maximum of axillary temperature, ${ }^{\circ} \mathrm{C}$.

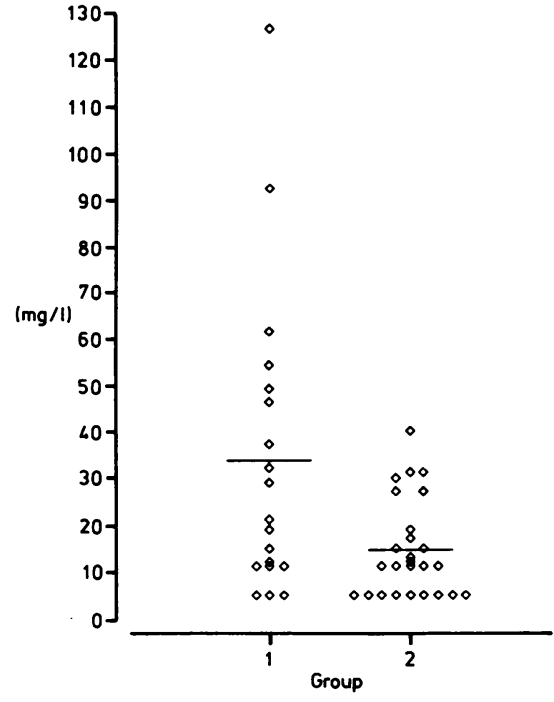

Maximum serum $C$-reactive protein concentration in all cases of acute deep lower limb venous thrombosis. Group 1, iliofemoral, group 2, tibial or popliteal thrombosis. The horizontal lines denote means of serum CRP. The difference between the medians was significant $p=0.02$ (Mann-Whitney $U$ test).

any other cause for the acute phase response. Treatment protocol at our hospital includes the combination of heparin and coumarine and only coumarine after discharge.

Peripheral blood leucocyte counts on admission were determined with an automatised calculator, and axillary temperatures and CRP concentrations were monitored throughout. Serum CRP was determined by an immunoturbidometric method (Orion Diagnostica, Espoo, Finland). The detection level for CRP at our hospital varied from $<10$ $\mathrm{mg} / \mathrm{l}$ to $<15 \mathrm{mg} / \mathrm{l}$ during the period concerned, but in those cases a serum CRP value of 5 $\mathrm{mg} / \mathrm{l}$ was used for statistical purposes. Data were compared with the non-paired Student's $t$ test, Mann-Whitney U-test, and Pearson's correlation analysis.

The 19 cases with iliofemoral thrombosis (group 1) were older than the 26 with the tibial or popliteal thrombosis (group 2), and the serum CRP response was higher in the former, but no such difference was seen in leucocyte responses or axillary temperatures (table). Age itself did not seem to explain the differences in CRP response between these two groups when examined by Pearson correlation analysis $(r=0.24, p=0.24$ in group $1 ; r=0.24, p=0.33$ in group 2$)$. Axillary temperature, CRP, and leucocyte responses were similar in the 22 men and 23 women. Serum CRP peaked over two days in all except four cases.

Analysis of the individual responses showed more than one third $(35 \%)$ of the 26 patients in group 2 to have no CRP response (figure), while only three had a temperature of 
$>37.5^{\circ} \mathrm{C}$ and only two out of 25 patients had a leucocyte reaction of $>11.0 \times 10^{9} / 1$ during acute phase of thrombosis. Serum CRP did not rise in three cases out of the $19(15.8 \%)$ patients in the iliofemoral group, and only one patient had a temperature of $>37.5^{\circ} \mathrm{C}$ or a leucocyte response of $>11.0 \times 10^{9} / 1$. The sensitivity of serum CRP to show the presence of thrombosis was $72 \%(95 \%$ confidence interval 54 to $90 \%$ ) in group 1 and $32^{\circ}{ }_{0}(12$ to $52 \%)$ in group 2.

A recent study has proposed a $100 \%$ sensitivity of serum CRP for detecting deep venous thrombosis. ${ }^{2}$ According to our results, deep lower limb venous thrombosis seems to elicit only a slight or even undetectable acute phase response. The serum CRP was normal in more than one third of the cases with the thrombosis in the tibial or popliteal veins and undetectable in about $16 \%$ of the cases of iliofemoral thrombosis. In our series the sensitivity of serum CRP was low in the cases with the thrombosis in the tibial or popliteal vein $\left(32^{\circ}{ }_{0}\right)$, but clearly higher $(77 \%)$ in the cases of iliofemoral thrombosis. Perhaps most cases had femoral or iliac vein thrombosis. ${ }^{2}$ This could partly explain the differences between their results and ours. White cell leucocyte counts and axillary temperatures were usually normal in both of our groups. Thus deep lower limb thrombosis seems to be a weak inducer of the acute phase response and some other cause for induction of the acute phase response should be considered if serum CRP concentration is over $100 \mathrm{mg} / \mathrm{l}$. H SYRJÄLÄ

K HAUKIPURO H KIVINIEMI

National Public Health Institue, Oulu, Department of Surgery,

University of Oulu, Oulu, Department of Surgery, Oulu University Central Hospital,
Oulu, Finland

1 International Committee for Standardization in Haematology (Expert Panel on Blood Rheology). Guidelines on selection of laboratory tests for monitoring the acute phase response. J Clin Pathol 1988;41:1203-12.

2 Thomas EA, Cobby MJD, Davies ER, Jeans WD, Whicher JT. Liquid crystal thermography and $C$ reactive protein in the detection of deep venous thrombosis. Br Med J 1989; 299:951-2.

Light and electron microscopic demonstration of immune deposits in renal tissue

Al-Nawab and Davies have clearly shown how renal biopsy specimens embedded in Lowicryl K4M can be used for immunogold staining at both light and electron microscopic levels. ${ }^{1}$ We applied similar immunogold labelling, but used LR White resin because it is simpler and more rapid.

Renal tissue is fixed in $2 \%$ buffered formaldehyde for two hours at $4^{\circ} \mathrm{C}$, rinsed in distilled water, and dehydrated in $70 \%$, then $100 \%$ acetone, each for 30 minutes at $4^{\circ} \mathrm{C}$. Infiltration with LR White (Hard) resin (London Resin Company, Basingstoke, Hampshire) is also done at $4^{\circ} \mathrm{C}$ for a minimum of three hours. Blocks are then embedded in TAAB polypropylene capsules surrounded by crushed ice, using $1.5 \mu \mathrm{l}$ accelerator $/ \mathrm{ml}$ resin, for a total of two hours. The low accelerator:resin ratio, also advocated by Newman and Hobot, ${ }^{2}$ and heat sink are

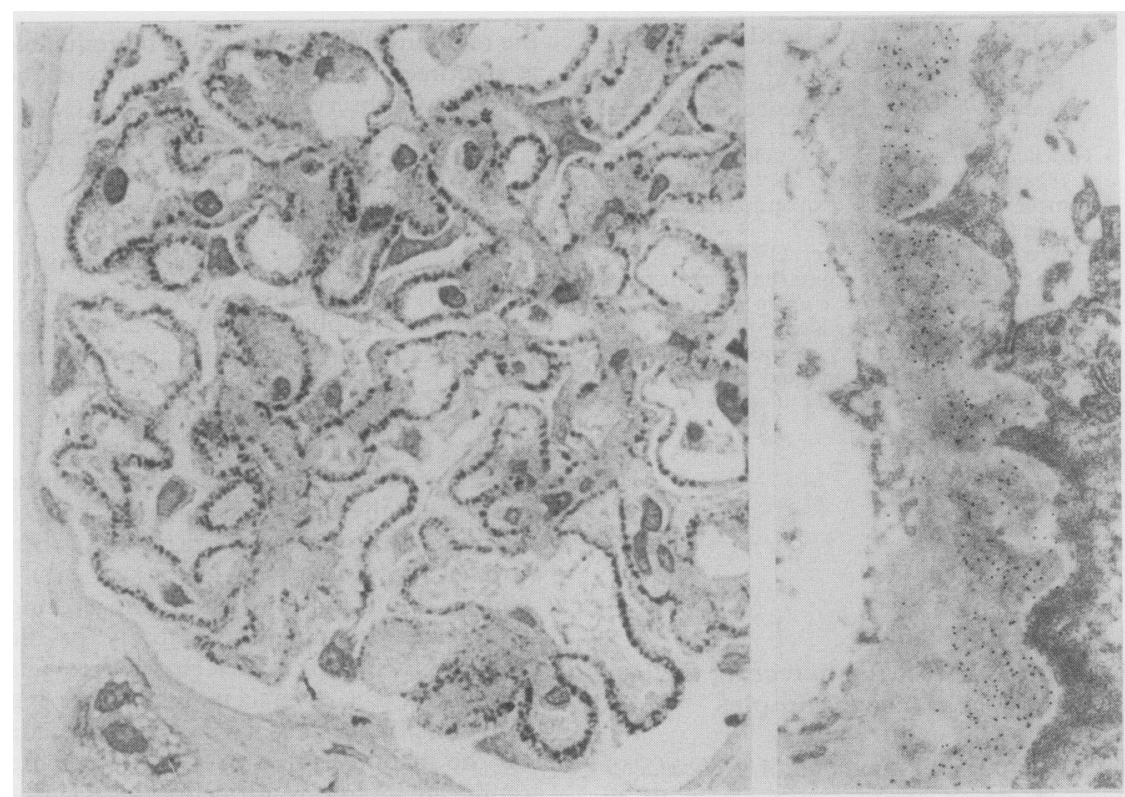

Membranous nephropathy. Left side (IGSS) shows granular staining for IgG along thickened capillary walls; right side (IGS) shows labelling for IgG in subepithelial dense deposits.

particularly important in limiting temperature rise during polymerisation so that crosslinkages are minimised and maximum antigenicity is retained.

The immunogold-silver (IGSS) and immunogold (IGS) staining methods used for 1-2 $\mu \mathrm{m}$ light microscopic or ultrathin electron microscopic sections are very similar to those described by Al-Nawab and Davies.

We have successfully shown immunoglobulin and complement $\mathrm{C} 3$ in appropriate patterns in a variety of glomerular diseases such as lupus nephritis, IgA nephropathy, and membranous nephropathy (figure). The Lowicryl method comprises nine procedural steps at -20 and $-35^{\circ} \mathrm{C}$, requires photopolymerisation, and lasts three to four days. The use of LR White resin has the major advantages of reducing the number of steps to five at $4^{\circ} \mathrm{C}$ and taking only eight hours.

$$
\begin{array}{r}
\text { AD MCKINNON } \\
\text { JG SIMPSON } \\
\text { Department of Pathology, } \\
\text { University of Aberdeen, } \\
\text { Foresterhill, Aberdeen AB9 } 2 Z D
\end{array}
$$

1 Al-Nawab MD, Davies DR. Light and electron microscopic demonstration of extracellular immunoglobulin deposition in renal tissue. $J$ Clin Pathol 1989;42:1104-8.

2 Newman GR, Hobot JA. Modern acrylics for post-embedding immunostaining techniques. J Histochem Cytochem 1987;35:971-81.

\section{BOOK REVIEWS}

Cancer Growth and Progression. Vols 110. Series Editor: Hans E Kaiser. Kluwer Academic Publishers. 1988-89. £60 per volume.

To try to cover the whole of contemporary knowledge on cancer in a series of 10 books is an audacious project. Hans Kaiser has gathered together nine distinguished colleagues and has tried to do the impossible. There is much in these volumes that will be of relevance to those interested in the biology of human, animal, and plant neoplasia. It should be said at the outset that it is rather difficult to identify the target audience for this series, and that such a project is inevitably going to suffer from the staggering rate at which new data are generated and interpretations of old data change.

In the first volume (Fundamental aspects of cancer. RH Goldfarb, ed), Goldfarb and colleagues have reviewed much of the basic information regarding the biology of cancer seen in most standard texts. In this and in the other volumes some contributions are rather esoteric and some poorly written. For example, what does the sentence, "Phylogeny is the accumulation of many ontogenies in the sense of hologeny" mean? The mechanisms of carcinogenesis are reviewed in volume 2 (Mechanisms of carcinogenesis. EK Weisberger, ed) but it is inevitable that the rapidly moving field of molecular oncology has ensured that many of the chapters are already rather dated. The burgeoning field of antioncogenes and tumour suppressor genes is scarcely mentioned. In the third and fourth volumes (volume 3 Influence of tumour development on the host. LA Liotta, ed; volume 4, Influence of the host on tumour development. RB Herberman, ed), the interactions between host and tumour are considered. Liotta's review of the mechanisms of cancer invasion and metastasis is masterful, yet has recently been covered in many other reviews. Similarly, Nicholson's coverage of the tumour cell surface is admirable, but has also been covered elsewhere.

The major part of the fifth volume (volume 5, Comparative aspects of tumour development. HE Kaiser, ed) is devoted to comparisons of taxonomy and morphology in tumours from different species, including plants. There are fascinating accounts of tumours in molluscs, arthropods, patterns of spread in fish and amphibians, cancer in reptiles and detailed discussion of better known tumours such as 